\title{
Impact Assessment of Trainings Imparted on Technical Know-How of Paper Patterns for Skill Improvement
}

\author{
Nisha Arya ${ }^{1^{*}}$ and Vivek Singh ${ }^{2}$ \\ ${ }^{1}$ Department of Textile and Apparel Designing, I.C. College of Home Science, \\ CCS HAU, Hisar-125004, Haryana, India \\ ${ }^{2}$ DES, Krishi Vigyan Kendra, Sonepat, Haryana, India \\ *Corresponding author
}

\section{A B S T R A C T}

The modern day woman faces various psychosocial barriers during lactation stage, in addition to the emotional and physical to assess clothing requirements. The problems and

\section{Keywords}

Psychosocial, Lactating, Paper pattern, Clothing, Psychological

Article Info

Accepted:

30 December 2017

Available Online:

10 January 2018 needs for clothing requirements of lactating mothers were identified by personally interviewing the subject. It was realized that there is great potential for the development and improvement of existing apparels for lactating stage. Designs were developed and garments were constructed for lactating mothers by incorporated garment challenges. A questionnaire was developed for personal interview. Preference for designs was taken by lactating mothers and top preferred designs were constructed. Specially designed and constructed Kameez were given to the lactating mothers for wear trial. Regarding preference of lactating mothers, design with vertical openings covered with jacket followed by design having side pleat, design with horizontal opening and design with yoke were the most preferred designs. Paper patterns of all the preferred designs were developed for proper dissemination of the developed designs. The aim of this study was to impart training on technical know-how of paper pattern developed for kameez designed for lactating mothers. Hence the study was planned with objectives of organization of training on technical know-how of paper patterns developed for kameez for urban lactating women and impact assessment of trainings.

\section{Introduction}

Clothing is one of the most important factors in the development of an individual personality. Clothing is one of the basic needs of our life. Every individual needs some kind of thing or other to protect, to cover and to beautify his/her body, which is of great importance to him/her. It influences a person socially, psychologically and emotionally (Arya and Singh, 2016). Every change in a life- situation-birth, entering school, college, getting a job, marriage, parenthood and even death requires a change in wardrobe even in the course of daily life, situation after situation requires a change in dress to facilitate and symbolize the situational change (Arya and Singh, 2017).

The experience of giving birth is a major turning point in women's lives. Mothers often identify childbirth as their most significant 
learning experience. The act of creation brings to the woman a new awareness of her creative capabilities. A mother will reassess her capabilities and her capacity to assume a new role as parent. Lactation is a period when women experiences physical as well as psychological changes. This period leads a woman to another level of maturity, i.e. her motherhood. She has her own demands and needs during this period, so her demand during lactation for dressing will be different from normal condition (Singh and Arya, 2017).

A mother tries to breastfeed discreetly with little of their body visible and chooses clothing that will cover her upper torso and allow her baby access to the breast. Her baby will obstruct her lower chest and abdomen from view. The wardrobes of most women should include many items suitable for breastfeeding.

Different types of clothing can be thinking of for lactation period. One type of clothing is a loose-fitted item the mother can open the midway. Two piece outfits, blouses, pullovers, sweaters and dresses with front or side openings are ideal. Blouses that button in the front can be unbuttoned from the bottom for good coverage. Dark patterned materials hide spots caused by milk leakage and natural fiber materials are the most suitable. (Lauwers and Swisher, 2005)

Just as planning for the baby's wardrobe helps a woman prepare mentally for the arrival of her baby, planning a cozy nursing corner can help her feel confident and prepared. The modern day woman faces various psychosocial barriers during lactation stage, in addition to the emotional and physical to assess clothing requirements. There is great potential for the development and improvement of existing apparels for lactating mothers. A study was conducted to design and develop functional clothing for lactating mothers. Paper patterns of selected designs were developed and trainings were imparted to the rural women and entrepreneurs.

\section{Technical Plan}

The problems and needs for clothing requirements of lactating mothers were identified personally by interviewing the subject. It was realized that there is great potential for the development and improvement of existing apparels for lactating stage. Designs were developed and garments were constructed for lactating mothers by incorporating garment challenges.

A questionnaire was developed for personal interview. Preference for designs was taken by lactating mothers and top preferred designs were constructed. Specially designed and constructed Kameez were given to the lactating mothers for wear trial. Paper patterns of all the preferred designs were developed for proper dissemination of the developed designs.

Two trainings of three days duration were organized for twenty students each of One year certificate course in Garment Construction and Hosiery of Textile and Apparel Designing Department and training of three days for twenty entrepreneurs of Hisar city was organized to impart technical knowhow on developed paper patterns developed for kameez for lactating mothers.

Opinion of trainees with reference to paper pattern technique, training and designs was assessed on five-point scale i.e. highly agreed, agreed, somewhat agreed, least agreed and disagreed scoring 5, 4, 3, 2 and 1 using selfdeveloped interview schedule. Weighted mean scores and Average mean scores were categorized as high (3.34-5.00), medium (1.67-3.33) and low (1.00-1.66) opinion. 


\section{Results and Discussion}

On the basis of existing clothing pattern of lactating mothers and problems encountered; fifteen designs of kameez were. Preferences of lactating mothers for developed designs were taken for selection of most preferred functional designs.

Top ranked six designs were constructed with bust size 36".

Design 1 - Vertical side openings at bust level with jacket covering the opening fastened with zipper

Front with round neck line

Back- plain with round shape neckline

Use of invisible zipper in vertical pattern at bust level for opening on both the sides

Contrast color jacket

Design 2 - Horizontal opening fastened with zipper at bust level with flap to cover the zipper

Front with V-shaped neck line

Back- plain with round shape neckline

Use of invisible zipper horizontal pattern at bust level for opening on both the sides

Matching flap to conceal zipper

Design 3 - Vertical side opening with side pleats closed with embroidery up to across front level

Front with U-shaped neck line and vertical pleats

Back- plain with round shape neckline
Vertical invisible zipper on both the sides at bust level for opening hidden under the lengthwise pleats

\section{Design 4 - Vertical long centre front opening fastened with buttons}

Front with round neck line

Back- plain with round shape neckline

Vertical long centre front opening fastened with buttons

Decorative buttons on the front opening

Embroidery for decoration

Design 5 - Vertical side openings in the princess line

Front with round neck line and piping at the princess line

Back- plain with round shape neckline

Invisible zipper at bust level for opening on both the sides inserted under the piping

Design 6 -Vertical side openings and yoke

Front with U-shaped neck line and contrasting color yoke with tucks

Back- plain with round shape neckline

Vertical invisible zipper at bust level for opening which is hidden under the yoke

These six designed kameez were tested on thirty urban lactating women to assess their suitability with respect to constructional and designing features. Paper patterns of all the six designs were prepared and multiplied. Two trainings of three days duration were organized on technical know- how of paper 
patterns developed for kameez for lactating mothers. Opinion of trainees with reference to paper pattern technique, training and designs was assessed.

\section{Opinion of trainees regarding paper pattern technique}

The data presented in table-1 depicts the opinion of trainees regarding paper pattern technique of designer kameez for lactating mothers. The trainees of training I opined that 'one can do the cutting independently by using paper patterns' (WMS 4.55), 'paper pattern is a time saving technique', and 'one can adopt garment construction as an income generating activity if paper patterns of different sizes are easily available' (WMS 4.50).

The trainees also opined that 'the use of paper patterns have given chance to stitch designer kameez for lactating women at home', \& 'it is worth spending money on paper patterns of kameez' (WMS 4.00), 'kameez stitched by using paper patterns have very good fitting' (WMS 3.65), 'paper pattern technique will increase the speed of garment construction' (WMS 3.50), and 'there is no need to learn drafting technique' (WMS 3.45).

Majority of the trainees of training II regarding opined that 'paper pattern is a time saving technique by using paper patterns' (WMS 4.55), 'one can do the cutting independently' (WMS 4.45), 'one can adopt garment construction as an income generating activity if paper patterns of different sizes are easily available' (WMS 4.40). The trainees also thought that 'paper pattern technique will increase the speed of garment construction' (WMS 3.65) followed by the opinion that 'use of paper pattern have given chance to stitch designer kameez for lactating women at home' (WMS 3.50), 'it is worth spending money on paper patterns of kameez for lactating women' (WMS 3.50) and 'kameez stitched by using paper patterns have very good fitting' (WMS 3.45 ) and 'there is no need to learn drafting technique' (WMS 3.45).

Hence, it can be concluded from the data that most of trainees had high opinion about the paper pattern technique as they opined that it is a time saving technique (4.52, Rank I), and by using paper pattern, one can do cutting independently (4.50, Rank II). They also opined that one can adopt garment construction as an income generating activity if paper patterns of different sizes are available (4.45, Rank III).

\section{Opinion of trainees regarding designs of kameez for lactating women}

The data furnished in the table- 2 depicts the opinion of trainees (Training I) regarding designs of kameez for urban lactating mothers. Majority of the trainees opined that 'the specific design features make the garment functional' (4.60), followed by the opinion that 'these designs are suitable to lactating women to feed the baby' (4.45), 'these designs are beautiful and functional' (4.40), 'these designs are as per latest fashion trend, $\&$ these designs can be made in other colors and print combinations' (4.30) and 'these designs are easy to stitch by using paper patterns, \& the developed designs are attractive' (4.25). Trainees also thought that 'these designs are comfortable for the lactating mothers' (4.15), 'making these designs is economical' (4.15) and 'these designs give ideas for other similar designs' (3.70).

Majority of the trainees (training II) opined high regarding designs of kameez for lactating women. The trainees opined that 'these designs are easy to stitch by using paper patterns' (4.65), followed by the opinion that 'the developed designs are attractive' (4.40) and 'the specific design features make the garment functional' (4.25). 
Table.1 Opinion of trainees regarding paper pattern technique

\begin{tabular}{|c|c|c|c|c|c|}
\hline \multirow[t]{2}{*}{$\begin{array}{l}\text { Sr. } \\
\text { No. }\end{array}$} & \multirow[t]{2}{*}{ Statements } & Training I & $\begin{array}{l}\text { Training } \\
\text { II }\end{array}$ & \multirow[t]{2}{*}{$\begin{array}{l}\text { Average } \\
\text { Score }\end{array}$} & \multirow[t]{2}{*}{ Rank } \\
\hline & & $\begin{array}{l}\text { WMS } \\
(\mathbf{n}=20)\end{array}$ & $\begin{array}{l}\text { WMS } \\
(\mathbf{n}=20)\end{array}$ & & \\
\hline 1. & $\begin{array}{l}\text { By using paper patterns, one can do the } \\
\text { cutting independently }\end{array}$ & 4.55 & 4.45 & 4.50 & II \\
\hline 2. & $\begin{array}{l}\text { Use of paper patterns give chance to stitch } \\
\text { designer kameez at home }\end{array}$ & 4.00 & 3.50 & 3.75 & IV \\
\hline 3. & $\begin{array}{l}\text { The paper pattern technique will increase the } \\
\text { speed of garment construction }\end{array}$ & 3.50 & 3.45 & 3.47 & VIII \\
\hline 4. & $\begin{array}{l}\text { It is worth spending money on paper patterns } \\
\text { of kameez }\end{array}$ & 4.00 & 3.50 & 3.75 & IV \\
\hline 5. & $\begin{array}{l}\text { Kameez stitched by using paper patterns } \\
\text { have good fitting }\end{array}$ & 3.65 & 3.45 & 3.55 & VI \\
\hline 6. & $\begin{array}{l}\text { One can adopt garment construction as an } \\
\text { income generating activity if paper patterns } \\
\text { of different sizes are easily available }\end{array}$ & 4.50 & 4.40 & 4.45 & III \\
\hline 7. & There is no need to learn drafting technique & 3.45 & 3.65 & 3.55 & VI \\
\hline 8. & Paper pattern is time saving technique & 4.50 & 4.55 & 4.52 & I \\
\hline
\end{tabular}

High (3.34-5.00), medium (1.67-3.33) and low (1.00-1.66) opinion

Table.2 Opinion of trainees regarding designs of kameez for lactating mothers

\begin{tabular}{|c|c|c|c|c|c|}
\hline \multirow{2}{*}{$\begin{array}{l}\text { Sr. } \\
\text { No. }\end{array}$} & \multirow{2}{*}{ Statements } & Training I & Training II & \multirow{2}{*}{$\begin{array}{l}\text { Average } \\
\text { score }\end{array}$} & \multirow[t]{2}{*}{ Rank } \\
\hline & & WMS $(n=20)$ & WMS $(n=20)$ & & \\
\hline$\overline{1 .}$ & $\begin{array}{l}\text { The specific design features make the } \\
\text { garment functional }\end{array}$ & 4.60 & 4.25 & 4.42 & II \\
\hline 2. & $\begin{array}{l}\text { These designs are as per latest fashion } \\
\text { trend }\end{array}$ & 4.30 & 4.15 & 4.22 & VI \\
\hline 3. & These designs are beautiful & 4.40 & 4.20 & 4.30 & IV \\
\hline 4. & The developed designs are attractive & 4.25 & 4.40 & 4.32 & III \\
\hline 5. & $\begin{array}{l}\text { These designs are easy to stitch by using } \\
\text { paper patterns }\end{array}$ & 4.25 & 4.65 & 4.45 & I \\
\hline$\overline{6 .}$ & $\begin{array}{l}\text { These designs can be made in other } \\
\text { colors and print combinations }\end{array}$ & 4.30 & 4.00 & 4.15 & VII \\
\hline 7. & $\begin{array}{l}\text { These designs give ideas for other } \\
\text { similar designs }\end{array}$ & 3.70 & 4.15 & 3.92 & VIII \\
\hline 8. & Making these designs is economical & 4.15 & 3.00 & 3.57 & $\mathrm{X}$ \\
\hline 9.. & $\begin{array}{l}\text { These designs are comfortable for the } \\
\text { lactating mothers }\end{array}$ & 4.15 & 3.50 & 3.82 & IX \\
\hline 10. & $\begin{array}{l}\text { These designs are suitable for lactating } \\
\text { mothers }\end{array}$ & 4.45 & 4.15 & 4.30 & IV \\
\hline
\end{tabular}

High (3.34-5.00), medium (1.67-3.33) and low (1.00-1.66) opinion 
Table.3 Opinion of trainees regarding training technique

\begin{tabular}{|c|c|c|c|c|c|}
\hline \multirow{3}{*}{$\begin{array}{l}\text { Sr. } \\
\text { No. }\end{array}$} & \multirow{3}{*}{ Statements } & & & \multicolumn{2}{|c|}{$\mathrm{N}=40$} \\
\hline & & Training 1 & $\begin{array}{l}\text { Training } \\
\text { II }\end{array}$ & $\begin{array}{l}\text { Average } \\
\text { Score }\end{array}$ & Rank \\
\hline & & $\begin{array}{r}\text { WMS } \\
(\mathbf{n}=\mathbf{2 0})\end{array}$ & $\begin{array}{l}\text { WMS } \\
(\mathrm{n}=\mathbf{2 0})\end{array}$ & & \\
\hline 1. & $\begin{array}{l}\text { The training has helped trainees to learn easy } \\
\text { method of cutting and stitching by using paper } \\
\text { patterns }\end{array}$ & 4.25 & 4.50 & 4.37 & I \\
\hline 2. & $\begin{array}{l}\text { The trainees acquired sufficient skill to use } \\
\text { paper patterns for construction of kameez }\end{array}$ & 4.60 & 4.15 & 4.37 & I \\
\hline 3. & $\begin{array}{l}\text { The trainees acquired sufficient knowledge } \\
\text { about different types of fabrics, trimmings and } \\
\text { embellishment materials used for designer } \\
\text { kameez }\end{array}$ & 3.55 & 3.50 & 3.52 & V \\
\hline 4. & $\begin{array}{l}\text { Instructions given on paper patterns and } \\
\text { envelope are easy to understand and self- } \\
\text { explanatory }\end{array}$ & 4.00 & 4.15 & 4.07 & III \\
\hline 5. & $\begin{array}{l}\text { Trainees could not stitch kameez designed for } \\
\text { lactating mothers independently before } \\
\text { training }\end{array}$ & 4.20 & 4.00 & 4.10 & IV \\
\hline
\end{tabular}

High (3.34-5.00), medium (1.67-3.33) and low (1.00-1.66) opinion

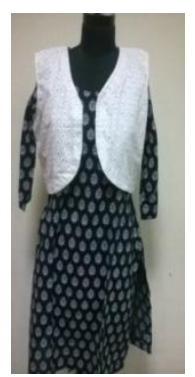

Design 1

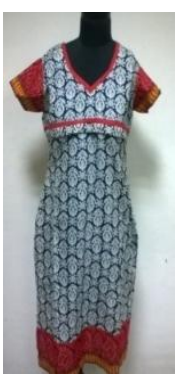

Design 2

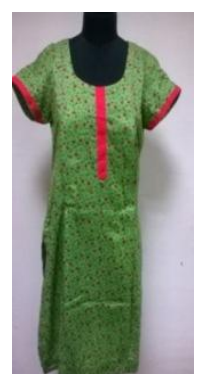

Design 3

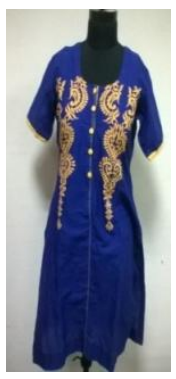

Design 4

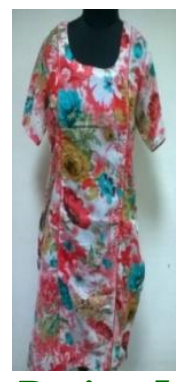

Design 5

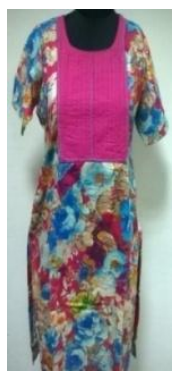

Design 6
The trainees also opined that 'these designs are beautiful' (4.20), 'these designs are as per latest fashion trend' (4.15), 'give ideas for other similar designs' (4.15), 'suitable for lactating mothers to feed the baby' (4.15), 'these designs can be made in other colors and print combinations' (4.00), and 'these designs are comfortable for the lactating mothers' (3.50). The trainees also thought that 'making these designs are economical' (3.00). Thus, it can be concluded that trainees had high opinion regarding designs of kameez for lactating mothers. The trainees were of the view that these are easy to stitch by using paper patterns $(4.45, I)$, the specific design features make the garment functional (4.42, II), and the developed designs are attractive (4.32, III).

\section{Opinion of trainees regarding training technique}

The opinion of trainees regarding training technique of designer kameez for lactating 
women has been depicted in table 3. Majority of the trainees opined that 'the trainees acquired sufficient skill to use paper patterns for construction of kameez' (4.60) and 'the training has helped trainees to learn easy method of cutting and stitching by using paper patterns' (4.25). The trainees also opined that 'they could not stitch kameez designed for lactating women independently before training' (4.20), followed by the opinion that 'the instructions given on paper patterns and envelope are easy to understand and self-explanatory' (4.00), and 'the trainees acquired sufficient knowledge about different types of fabrics, trimmings and embellishment materials used for designer kameez' (3.55).

The opinion of trainees of training II regarding training technique of designer kameez for lactating women depicts that they had high opinion about the training as they opined that 'training has helped trainees to learn easy method of cutting and stitching by using paper patterns' (4.50). The respondents also opined that 'the trainees acquired sufficient skill to use paper patterns for construction of kameez for lactating women' (4.15),followed by the opinion that 'instructions given on paper patterns and envelope are easy to understand and selfexplanatory' (4.15), 'trainees could not stitch kameez designed for lactating women independently before training' (4.00) and 'the trainees acquired sufficient knowledge about different types of fabrics, trimmings and embellishment materials used for designer kameez' (3.50).
Thus, all the trainees were of the view that training helped them to learn the easy method of cutting and stitching by using paper patterns and the trainees acquired sufficient skill to use paper patterns $(4.37, \mathrm{I})$.

Developed paper patterns for designed and constructed Kameez for urban lactating mothers helped the trainees to learn the technique of stitching as paper pattern technique was found time saving as compared to drafting technique.

It is also considered as an easy method of cutting and stitching by using paper patterns.

\section{References}

Arya, N. and Singh, V. 2016. Preferences regarding constructional and designing features of kameez for urban lactating women. Indian Journal of Research. 5(10) 246-248.

Arya, N. and Singh, V. 2017. Existing clothing practices of urban lactating mothers. International Journal of Scientific Research. 6(4):451-452.

Lauwers, Judith and Swisher, Anna. 2005. Counseling the nursing mother-A lactation consultant's guide. Jones and Bartlett Publishers Boston.

Singh, V. and Arya, N. 2017. Clothing practices of rural lactating women. International Journal of Applied Research. 3(4):718-720.

\section{How to cite this article:}

Nisha Arya and Vivek Singh. 2018. Impact Assessment of Trainings Imparted on Technical Know-How of Paper Patterns for Skill Improvement. Int.J.Curr.Microbiol.App.Sci. 7(01): 3612-3618. doi: https://doi.org/10.20546/ijcmas.2018.701.424 